\title{
PENGARUH LATIHAN SAQ (SPEED, AGILITY, QUICKNESS) TERHADAP PENINGKATAN KELINCAHAN ATLET BULUTANGKIS KELOMPOK UMUR GANDA REMAJA PUTERI PB. DJARUM.
}

\author{
Ibnu Yunshor Amar \\ Ari Subarkah dan Hendro Wardoyo
}

\begin{abstract}
Abstrak. Penelitian ini bertujuan untuk mengetahui pengaruh latihan SAQ (Speed, Agility, Quickness) terhadap peningkatan kelincahan atlet bulutangkis kelompok umur ganda remaja puteri PB. Djarum.Teknik yang digunakan dalam pengambilan sampel adalah total sampling sehingga sampel yang digunakan berjumlah 8 orang.Instrumen penelitian yang digunakan dalam penelitian ini adalah Court Agility Test.

Hasil perhitungan mengenai tes awal dan tes akhir Court Agility Test diperoleh data sebagai berikut : selisih rata-rata (MD) 1,20 dengan standar deviasi perbedaan (SDD) 0,55, standar error perbedaan rata-rata (SEMD) 0,21 dalam perhitungan selanjutnya diperoleh nilai $t$-hitung sebesar 5,71 dan nilai $t$-tabel dengan derajat kebebasan (n-1) $=7$ dan taraf signifikan $\alpha=0,05$ didapat sebesar 2,81 yang berarti $t$-hitung $=5,71$ lebih besar dari $t$-tabel $=2,81$. Hal ini menunjukkan bahwa hipotesis nihil (H0) ditolak dan hipotesis alternatif (Hi) diterima. Dengan demikian hasil perhitungan tersebut menyatakan bahwa : latihan SAQ (Speed, Agility, Quickness) berpengaruh signifikan terhadap peningkatan kelincahan atlet bulutangkis kelompok umur ganda remaja puteri PB. Djarum.
\end{abstract}

Kata Kunci : Speed, Agility, quickness, bulutangkis

\section{PENDAHULUAN}

Pendekatan sport science yang digunakan baru-baru ini bertujuan untuk meningkatkan kemampuan individual, pasangan, tim dan tentunya peningkatan prestasi. Cara-cara latihan fisik dalam sport science dilaksanakan lebih detail dan progresif serta lebih mengacu pada data evaluasi (analisa gerak). Hal tersebut dikenal dengan istilah strength and conditioning.

Salah satu bentuk latihan peningkatan kelincahan dalam sport science adalah bentuk latihan $S A Q$ (Speed, Agility, Quickness). Latihan $S A Q$ menjadi bentuk pelatihan yang populer untuk peningkatan kondisi fisik dewasa ini. Padahal latihan $S A Q$ ini sudah berkembang dan dipakai sejak lama yaitu sejak tahun 1980-an yang berasal dari negara Amerika Serikat. Latihan $S A Q$ ini diterapkan oleh banyak pelatih American Football untuk meningkatkan kemampuan fisik atletatletnya, dan dikemudian hari latihan $S A Q$ tersebut menjadi inspirasi serta banyak digunakan oleh cabang olahraga lainnya.

Latihan $S A Q$ adalah sistem latihan progresif dan merupakan suatu pembinaan yang dirancang untuk mengembangkan serta mempersiapkan kemampuan motorik dasar sehingga mampu mengintegrasikannya ke dalam pola gerak pada masing-masing cabang olahraga. Pelatihan $S A Q$ ini juga memungkinkan atlet menjadi lebih baik dalam membaca dan bereaksi terhadap suatu rangsangan, bergerak secara efektif dan efisien ke segala arah serta mampu mengontrol keseluruhan gerak tubuhnya dengan koordinasi dan keseimbangan yang baik.

Pada saat perkembangan bulutangkis Indonesia yang kurang menggembirakan khususnya sektor pemain putri, maka pemain bulutangkis pada usia 
muda harus menjadi prioritas utama dan memerlukan perhatian yang lebih serius, serta harus berkesinambungan demi tercapainya prestasi yang tinggi. Untuk mendapatkan materi atlet-atlet yang berbakat sebagai generasi yang akan datang perlu dipersiapkan bibit yang akan menjadi tulang punggung prestasi nasional diawali dari usia anak-anak dan remaja (adolesensi).

Berdasarkan latar belakang diatas maka peneliti berkeinginanan melakukan penelitian untuk mengetahui sejauh mana pengaruh latihan SAQ (Speed, Agility, Quickness) terhadap peningkatan kelincahan atlet bulutangkis kelompok umur ganda remaja puteri PB. Djarum.

\section{LATIHAN.}

Latihan adalah merupakan suatu aktivitas olahraga yang sistematis, progresif, dan dilakukan dalam waktu yang panjang sesuai dengan tingkat individu, yang bertahan membentuk fungsi fisiologi manusia dan psikologi manusia untuk memenuhi syarat-syarat yang dibebankan padanya.

Faktor-faktor yang akan menunjang tingginya sebuah kualitas latihan, yakni sebagai berikut :
a. Pengetahuan dan kepribadian pelatih
b. Fasilitas dan peralatan
c. Kemampuan atlet, bakat dan motivasi
d. Pertandingan
e. Penemuan dari ilmu yang membantu

Prinsip-prinsip latihan adalah sebagai berikut
a. Perbedaan Individu
b. Penyesuaian tubuh (Adaptasi)
c. Overload
d. Reversibility
e. Spesifikasi
f. Variasi Latihan
g. Perencanaan Jangka Panjang

Persiapan-persiapan latihan itu meliputi :

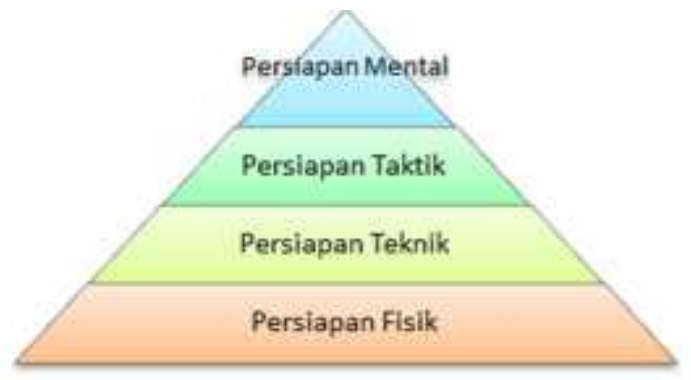

Gambar 1 : Piramida Faktor-Faktor Latihan Sumber : Tudor Bompa, Theory and Methodology of Training, (Dubuque Lowa: Kendall/Hunt Publishing Company, 1994)

a. Persiapan Fisik

Sasaran latihan fisik adalah perbaikan kualitas sistem otot untuk meningkatkan kemampuan biomotor dan perbaikan sistem energi sebagai sumber tenaga. Sejalan dengan itu Bompa berpendapat dalam bukunya bahwa tujuan utama dari latihan fisik adalah untuk meningkatkan potensi fungsional atlet dan mengembangkan kemampuan biomotor ke standar yang lebih tinggi.

b. Persiapan Teknik

Sasaran latihan teknik sendiri adalah untuk meningkatan efesiensi gerak. Oleh karena itu, penguasaan teknik perlu dibina dan diteliti, secara cermat dan teratur, dengan frekuensi ulangan yang banyak, sehingga akhirnya dapat dikuasai dengan baik secara otomatis.

\section{c. Persiapan Taktik}

Sasaran dari latihan taktik yakni adalah untuk mengembangkan pola pikir dalam bertanding. Atlet harus dilatih dan belajar semua jenis taktik karena pertandingan yang dijalani nantinya sangatlah dinamis yang sewaktu-waktu dituntut untuk cepat merubah taktik permainan. faktor-faktor pendukung untuk menunjang keberhasilan suatu kecakapan taktik adalah : 
1. Kemampuan fisik.

2. Kemampuan teknik.

3. Team work.

4. Distribusi energi.

5. Penguasaan pola pertandingan.

\section{d. Persiapan Mental}

Sasaran dari latihan mental adalah untuk meningkatkan disiplin, semangat daya juang, kepercayaan diri dan keberanian serta untuk mematangkan emosi.

Hadisasmita dan Syarifuddin mengemukakan hal-hal yang perlu diusahakan dan mendapat perhatian dalam pembinaan mental yakni :

1) Kemampuan kemauan (Will Power)

2) Semangat daya juang (Fighting Spirit)

3) Kemampuan dalam menghadapi kesukaran atau kegagalan.

4) Percaya diri (Self Confidence)

5) Menghindarkan percaya diri yang berlebihan (Over Confidence).

Berdasarkan teori-teori diatas dapat disimpulkan latihan adalah suatu aktifitas olahraga yang dilakukan secara sistematis yang di dalamnya terdapat persiapanpersiapan seperti persiapan fisik, teknik, taktik dan mental sesuai dengan tujuan yang ingin dicapai.

\section{SAQ (SPEED, AGILITY, QUICKNESS)}

Latihan $S A Q$ melibatkan latihan yang progresif untuk mengembangkan kemampuan seorang atlet untuk lebih terampil pada kecepatan yang lebih cepat dan lebih presisi. Brown dan Ferriano mengemukakan beberapa manfaat yang bisa didapat dari latihan $S A Q$ ini meliputi peningkatan kekuatan otot, efisiensi sinyal otak, kesadaran spesial kinestetik, keterampilan motorik dan waktu reaksi. Brown dan Ferriano mengemukakan beberapa manfaat yang bisa didapat dari latihan $S A Q$ ini meliputi peningkatan kekuatan otot, efisiensi sinyal otak, kesadaran spesial kinestetik, keterampilan motorik dan waktu reaksi.

Persyaratan yang harus dimiliki atlet untuk mendapatkan kualitas kecepatan yang istimewa $(S A Q)$ yaitu :

a. Latihan kekuatan maksimal secara ekslusif, karena "hanya mereka yang mempunyai kekuatan maksimal-lah yang dapat bergerak dengan cepat".

b. Latihan daya tahan kecepatan, agar mampu mempertahankan irama gerak cepat dalam jumlah pengulangan yang cukup banyak dan bertahan dalam waktu yang relative lama.

c. Metode latihan yang tepat untuk meningkatkan kemampuan kecepatan gerak adalah metode repetisi.

Speed.

Kecepatan adalah gerakan atau perjalanan yang dengan waktu singkat dapat mencapai jarak yang panjang. Dalam terminologi olahraga kecepatan dapat juga dikatakan sebagai jarak perwaktu. Artinya kecepatan diukur melalui suatu jarak dibagi dengan suatu unit tertentu. Sebagian besar tes yang dilakukan dengan cara mengukur jaraktotal dibagi oleh total waktu yang diperlukan untuk menempuh jarak tersebut. Oleh karena itu, biasanya mengukur kecepatan rata-rata yakni adalah :

\section{kecepatan rata-rata $=$ jarak total : total waktu}

Johansyah Lubis dalam bukunya membagi kecepatan lari garis lurus atas tiga tahap yakni

1. Akselerasi,

2. pencapaian kecepatan maksimal

3. pemeliharaan kecepatan maksimal.

Gerakan yang mengandung unsur kecepatan dalam permainan bulutangkis adalah ketika pemain sedang menyongsong shuttlecock yang jauh dari posisi berdirinya. Misalnya dalam permainan ganda yaitu ketika pemain depan melakukan netting 
kemudian oleh lawan shuttlecock diangkat tinggi ke belakang, saat pemain belakang mengejar shuttlecock untuk melakukan smash

Dalam merancang bentuk latihan speed, pelatih dapat melakukan modifikasi jarak, durasi, repetisi, set, volume dan recovery tergantung dari kebutuhan cabang olahraga. Adapun bentuk-bentuk latihan untuk meningkatkan kecepatan yakni antara lain :

1. ladder drill

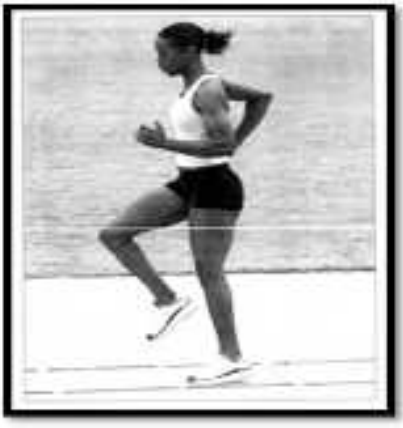

Gambar 1

2. Run Through with Hurdle

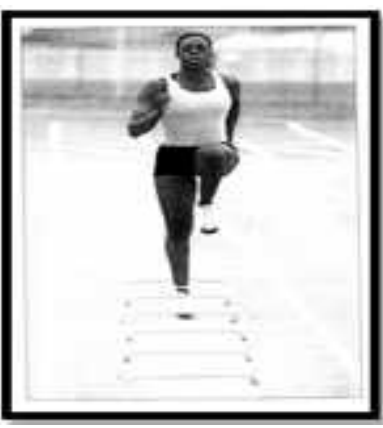

Gambar. 2

3. Wall Drills (Acceleration Marches)

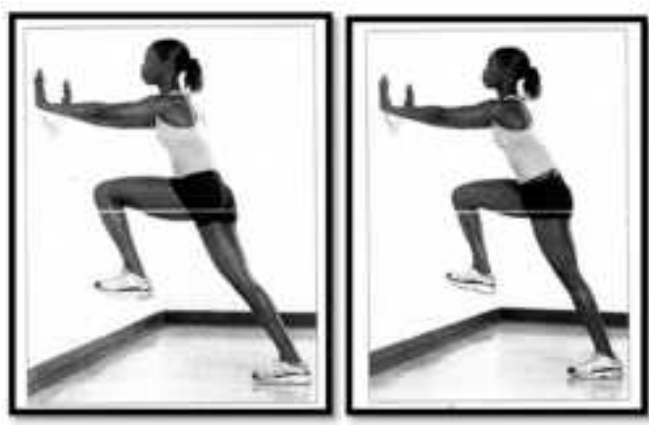

Gambar 3

\section{4. $\quad$ Falling Start}

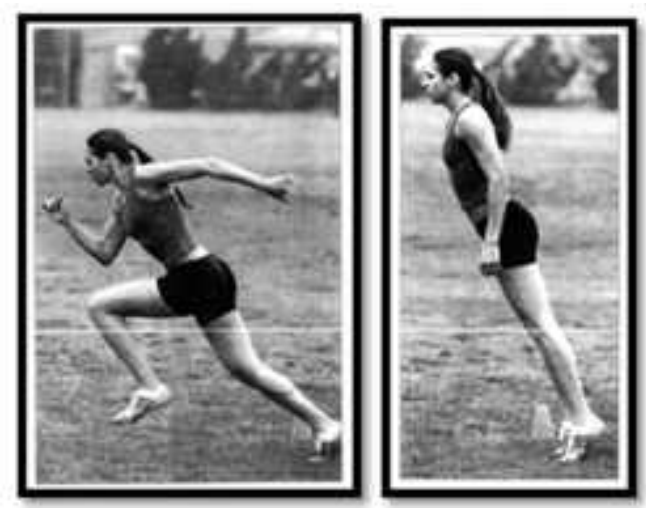

Gambar 4

\section{5. $\quad$ Partner-Resisted Starts}

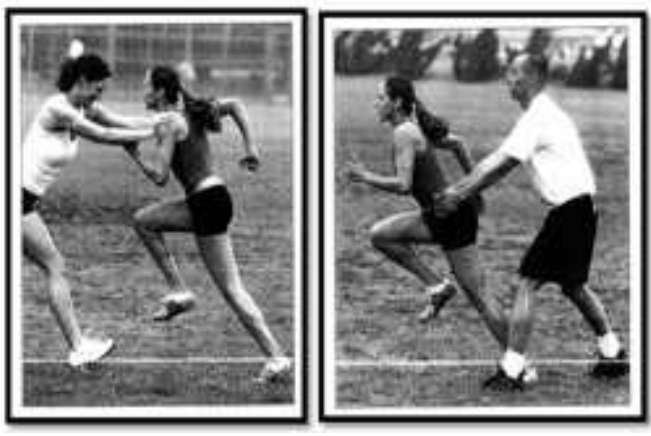

Gambar 5

Gambar 1, 2, 3, 4,5

Sumber: Lee E. Brown dan Vance A. Ferrigno, Training For Speed, Agility and Quickness,(USA : Human Kinetics, 2005)

\section{Agility (Kelincahan)}

Kelincahan berasal dari kata lincah yang berarti selalu bergerak-gerak, tidak dapat diam, tidak tenang. Kelincahan disini digambarkan seperti anak kecil yang aktif yang selalu bergerak kesana-kemari, tidak bisa diam.

Sajoto mengatakan kelincahan adalah kemampuan seseorang merubah posisi di area tertentu. Penggambarannya yaitu seperti atlet aerobic gymnastic yang merubah posisi tubuhnya, berputar-putar dihampir setiap sudut lantai senam. Johansyah Lubis dalam bukunya 
mengatakan kelincahan adalah seperangkat keterampilan kompleks yang dilakukan oleh seseorang untuk merespon stimulus eksternal dengan perlambatan, perubahan arah dan reacceleration.

Berdasarkan ungkapan dari 3 ahli diatas terdapat ada beberapa hal yang menjadi karakteristik kelincahan, yaitu kecepatan dan ketepatan perubahan arah lari, perubahan posisi tubuh, dan perubahan arah bagian-bagian tubuh (body movement).

Gerakan dalam permainan bulutangkis yang mengandung unsur kelincahan adalah saat terjadinya rally panjang, saat itulah terlihat shuttlecock yang dipukul oleh lawan mengarah ke segala penjuru lapangan yang memaksa pemain untuk bergerak, merubah arah, merubah posisi sambil tetap menjaga keseimbangan tubuh untuk mengejar shuttlecock tersebut dan mengembalikannya lagi ke lawan dengan pukulan yang baik.

Contoh-contoh latihan untuk meningkatkan kelincahan antara lain :

1. Carioca

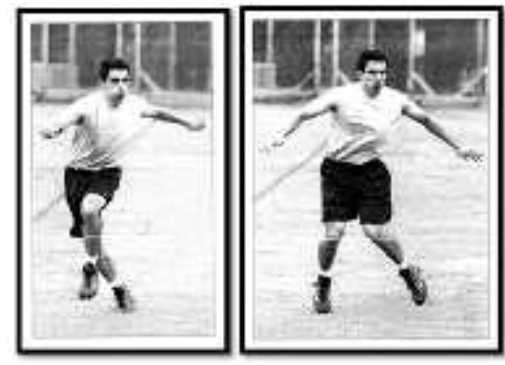

Gambar 6

2. Square Drill (Variation : carioca, shuffle step or hop on one foot)

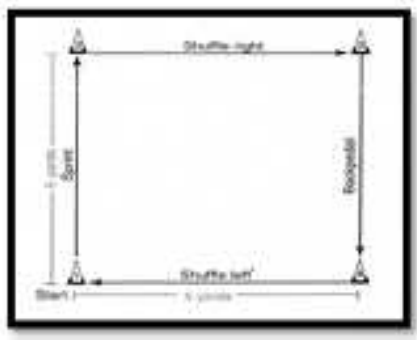

Gambar 7
3. Star Drill (Variation : carioca or shuffle step)

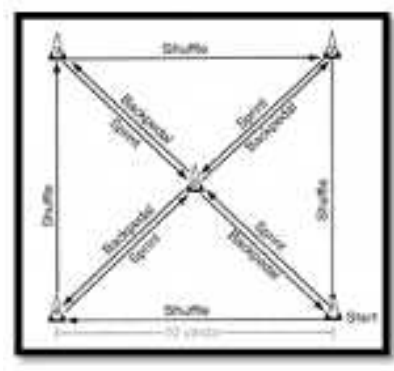

Gambar 8

4. $\quad$ In - Out Shuffle (ladder drill)

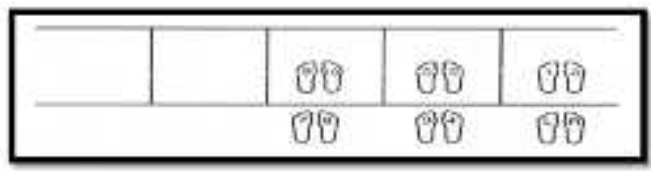

Gambar 9

5. $\quad 180$ - Degree Turn (ladder drill)

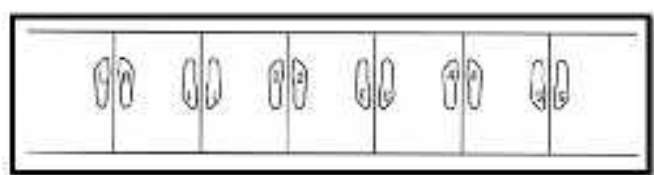

Gambar 10

6. T Crul Drill

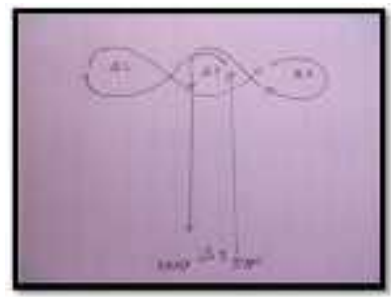

Gambar 11

Gambar 6,7,8,9,10 dan 11

Sumber : Lee E. Brown dan Vance A.

Ferrigno, Training For Speed, Agility and

Quickness, USA : Human Kinetics, 2005

\section{Quickness (Kecepatan Merespon)}

Quickness adalah kecepatan gerak aksi (tanpa stimulus), atau reaksi, reaksi optic-akustik-taktil (seperti gerak menendang, gerak memukul, duduk berdiri, 
gerak dengan berbagai posisi, baik yang diawali dengan stimulus atau tanpa stimulus) dan dapat dilakukan dengan reaksi sederhana atau reaksi kompleks.

Ketika melatih quickness, hal yang perlu diingat adalah saat atlet melakukan gerakan-gerakan ini harus selalu ada peningkatan yakni dari :

a. Lambat ke cepat

b. Mudah ke sulit

c. Aktif ke reaktif

d. Terduga ke tidak terduga

e. Rendah ke tinggi

Gerakan sederhana quickness di bulutangkis yaitu saat mengawali permainan. Ketika pemain bersiap menerima servis dari lawan, apalagi di dalam permainan ganda apabila pemain bisa menerima servis dengan baik, maka dapat langsung dengan mudah untuk mematikan lawan. pelatih untuk dapat memberikan porsi tersendiri untuk melatih gerakan quickness dalam bulutangkis.

Adapun bentuk latihan untuk melatih gerakan quickness antara lain :

1. Ball Drops With a Partner

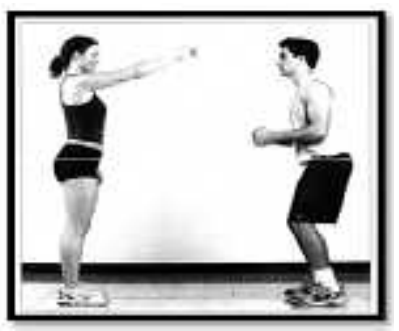

Gambar 12

2. Mirror Drills In Box

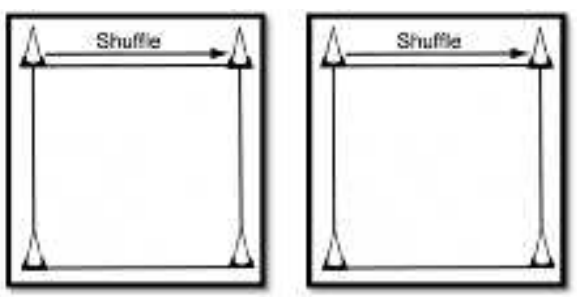

Gambar 13
3. Who Threw ?
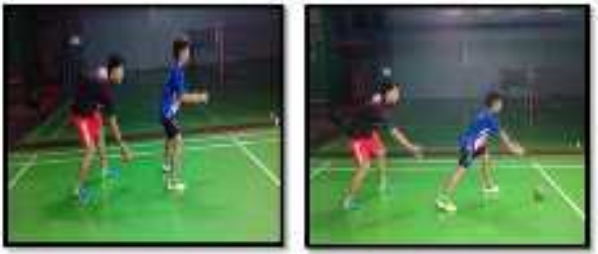

Gambar 14

4. $\quad$ Passing All Direction

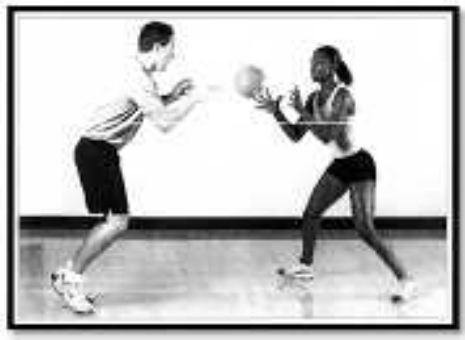

Gambar 15

5. $\quad$ Drop and Get Up

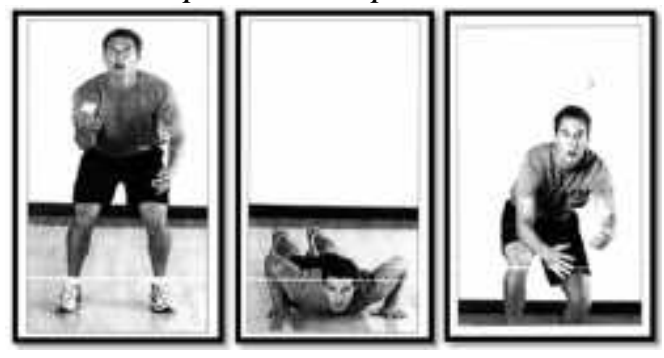

Gambar 16

6. Barier Jump With Cut and Sprint

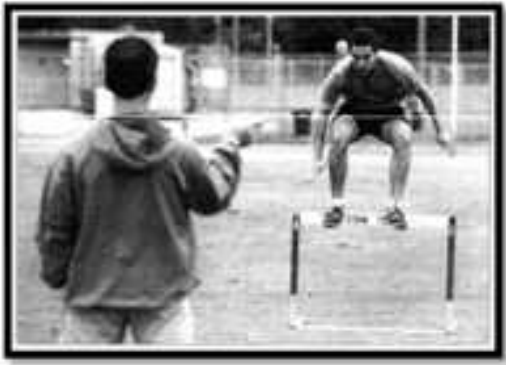

Gambar 17 
7. Sit or Lying to Stand Pop Up

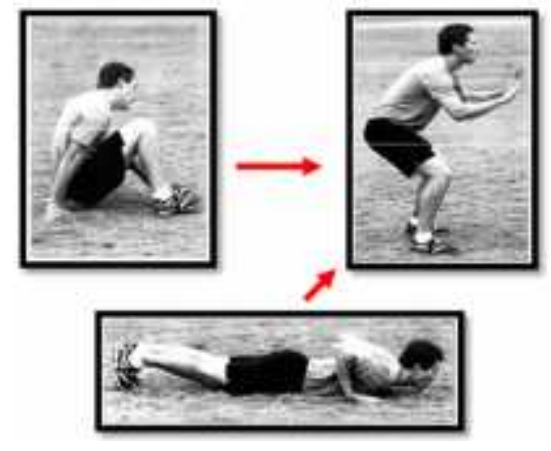

Gambar 18

Gambar 12 s.d 18

Sumber : Lee E. Brown dan Vance A. Ferrigno, Training For Speed, Agility and Quickness, USA : Human Kinetics, 2005

Bentuk latihan $S A Q$ ini dapat dimodifikasi sesuai dengan kebutuhan dan karakeristik cabang olahraga yang digeluti sesuai dengan kreatifitas dan analisa yang tajam dari seorang pelatih. Untuk memperoleh hasil yang maksimal sebaiknya sebelum masuk ke latihan ini didahului dengan pemanasan yang cukup, mempersiapkan otot-otot yang akan bekerja dan akan melibatkan sendi-sendi yang lebih luas pergerakannya.

Kelincahan dalam permainan bulutangkis sangat diperlukan untuk melakukan teknik footwork (gerakan kaki). Footwork adalah gerakan-gerakan langkah kaki yang mengatur badan untuk menempatkan posisi badan, agar memudahkan pemain dalam melakukan gerakan memukul shuttlecock sesuai dengan posisinya.

Efektifitas pemain atlet bulutangkis dalam gerak langkah kaki dengan tangan yang sama akan mempermudah jangkauan atau pengambilan shuttlecock.

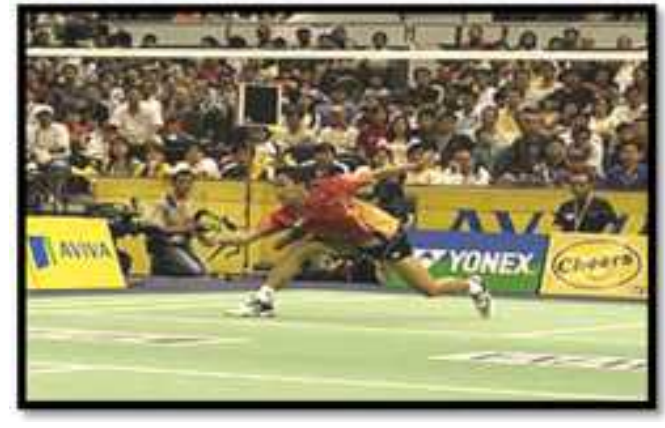

Gambar 19. Footwork bulutangkis

Sumber : www.bulutangkis.com, (Jakarta :

23 September 2015)

Dalam bermain ganda bulutangkis, langkah kaki harus sangat terampil untuk memudahkan dalam berotasi, sehingga seluruh lapangan dapat tercover dengan sempurna serta menciptakan pukulan yang baik, agar lebih mudah menempatkan shuttlecock ke area yang kosong

Dasar langkah kaki ada enam arah untuk melangkah dalam permainan bulutangkis yaitu; melangkah ke kiri muka dan kanan muka, melangkah ke samping kiri dan samping kanan, melangkah ke kanan belakang dan kiri belakang.

\section{PERMAINAN \\ BULUTANGKIS}

GANDA

Permainan ganda adalah permainan dua lawan dua. Hal ini sangat berbeda dengan permainan tunggal, khususnya karena atlet bermain dengan pasangan, sehingga biasanya memiliki lebih sedikit waktu untuk berpikir dan bereaksi. Terdapat tiga nomor ganda dalam bulutangkis yaitu : ganda putra, ganda putri dan ganda campuran (satu pasang terdiri dari seorang putra dan seorang putri).

Permainan ganda bulutangkis adalah permainan yang mengandalkan kerjasama. Kedua pemain harus dalam satu kesatuan sehingga mereka harus bermain menurut suatu bentuk permainan yang terstruktur, berarti kerjasama harus lebih 
diutamakan daripada bermain secara perseorangan. Kerjasama diantara kedua pasangan akan lebih mudah jika terdapat komunikasi satu sama lain.

\section{TEKNIK BULUTANGKIS}

Teknik dasar adalah keterampilan dasar bulutangkis yaitu pegangan (grip), pukulan (stroke) dan gerakan kaki (Footwork).

a. Pegangan (grip)

Pegangan raket yang benar adalah memanfaatkan tenaga dari pergelangan tangan. pegangan raket dalam bulutangkis dibagi empat jenis, yaitu forehand grip, backhand grip, american Grip dan combination grip.

b. Pukulan (stroke)

Teknik pukulan dalam bulutangkis dibagi menjadi tiga bagian yang terdiri dari

- pukulan bawah (under arm stroke) yaitu servis, under arm lob, pukulan netting,

- pukulan lurus atau samping (mendatar/drive) yaitu lob/clear, drive, dropshoot, placing

- pukulan atas (overhead stroke) yaitu Overhead lob, Overhead smash, chop, dropshot.

\section{TAKTIK DAN STRATEGI BULUTANGKIS}

Strategi secara harfiah adalah suatu rencana yang cermat mengenai kegiatan untuk mencapai sasaran khusus. Dalam ganda bulutangkis terdapat tiga formasi yang dapat digunakan untuk strategi memenangkan pertandingan. Formasi itu meliputi :

a. Formasi berisisian/bertahan (side by side formation),

b. formasi satu di depan dan satu dibelakang/menyerang ( $U p$ and back formation),

c. Formasi Kombinasi.

\section{KERANGKA BERPIKIR}

Bulutangkis merupakan olahraga yang pergerakannya multi-direction, bergerak ke segala arah bahkan ada yang sampai memutar tubuh untuk menjangkau shuttlecock. Pemain harus cepat dan tepat bergerak untuk menjangkau shuttlecock sambil menjaga keseimbangan tubuhnya, sehingga pukulan yang dilancarkan tetap memiliki akurasi yang bagus.

Agility yang dibutuhkan dalam bulutangkis adalah kelincahan yang mampu bertahan lama dalam menjangkau shuttlecock yang mengarah ke setiap sudut lapangan selama rally berlangsung.

Dalam permainan bulutangkis, quickness selalu terjadi dalam setiap rally yaitu saat pemain melihat dan mendengar shuttlecock dipukul oleh lawan yang kemudian dengan segera merespon dengan bergerak untuk menjangkau kemana shuttlecock tadi diarahkan untuk kemudian melakukan pukulan pengembalian. Quickness adalah kecepatan gerak aksi yang dilakukan tubuh atas stimulus yang diberikan.

\section{PENGAJUAN HIPOTESIS}

Berdasarkan dari kerangka teori dan kerangka berpikir yang telah dikemukakan sebelumnya, pada bagian ini dibuat hipotesis yang merupakan jawaban sementara yang selanjutnya akan dibuktikan kebenarannya melalui penelitian yang akan dilakukan. Hipotesis yang diajukan dalam penelitian ini adalah latihan $S A Q$ (Speed, Agility, Quickness) dapat berpengaruh meningkatkan kelincahan atlet bulutangkis kelompok umur ganda remaja puteri PB. Djarum. 


\section{METODE PENELITIAN}

Penelitian ini bertujuan untuk mengetahui pengaruh latihan SAQ (Speed, Agility, Quickness) terhadap peningkatan kelincahan atlet bulutangkis kelompok umur ganda remaja putri PB. Djarum.

Rancangan metode eksperimen yang digunakan dalam penelitian ini adalah metode penelitian eksperimen preexperimental designs dengan pendekatan one group pre test - post test design yaitu untuk mengetahui variabel bebas terhadap variabel terikat.

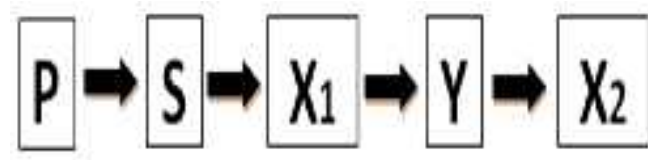

Keterangan :

P : Populasi

S : Sampel

X1 : Pre Test (Tes Awal)

$\mathrm{Y}$ : Latihan $S A Q$

X2 : Post Test (Tes Akhir)

Populasi dan Teknik Pengambilan Sampel

Populasi adalah seluruh atlet bulutangkis kelompok umur ganda remaja putri PB. Djarum yang berjumlah 8 orang. peneliti menggunakan seluruh populasi sebagai sampel dengan teknik yang digunakan dalam pengambilan sampel adalah total sampling atau boring sampling yakni jumlah keseluruhan populasi dijadikan sampel.

Instrumen Penelitian

Dalam penelitian ini data diambil dengan cara mengukur kelincahan menggunakan Court Agility Test dengan dicatat hasil waktu yang dicapai menggunakan stopwatch. Tes dilakukan sebanyak dua kali yaitu sebelum diberikan latihan $S A Q$ dan sesudah diberikan latihan $S A Q$.

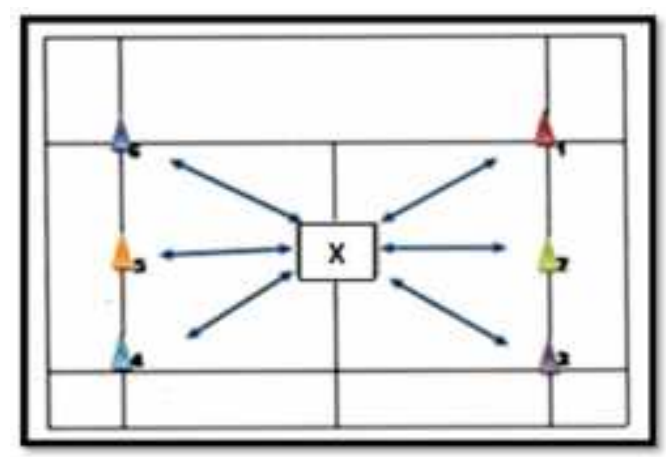

Gambar 18: Court Agility Test.

Sumber : A. KH Basri Yusuf, Kriteria Dan Parameter Fisik Atlet Masuk Pelatnas Dan Atlet Pelatnas (Indonesia : PBSI, 2014)

\section{HASIL PENELITIAN}

Hasil penelitian dan pengamatan data yang telah terkumpul dapat dideskripsikan data penelitian ini meliputi nilai tertinggi, nilai rata-rata, standar deviasi, standar eror, distribusi frekuensi, serta grafik batang dari masing-masing variabel, data lengkapnya sebagai berikut :

Tabel 1.

Deskripsi Data Penelitian

\begin{tabular}{|c|c|c|}
\hline Variabel & $\begin{array}{c}\text { Hasil tes } \\
\text { awal } \\
\text { Court } \\
\text { Agility Test } \\
\text { (detik) }\end{array}$ & $\begin{array}{c}\text { Hasil tes } \\
\text { akhir } \\
\text { Court } \\
\text { Agility Test } \\
\text { (detik) }\end{array}$ \\
\hline Nilai Tertinggi & 14,46 & 13,17 \\
\hline Nilai Terendah & 12,69 & 11,55 \\
\hline Rata-Rata & 13,58 & 12,38 \\
\hline $\begin{array}{c}\text { Standar } \\
\text { Deviasi }\end{array}$ & 0,60 & 0,53 \\
\hline Standar Error & 0,23 & 0,20 \\
\hline
\end{tabular}

Data Hasil Pengukuran Tes Awal dan Tes Akhir Court Agility Test

a. Tes Awal

Data yang terkumpul mengenai pengaruh latihan SAQ (Speed, Agility, Quickness) terhadap peningkatan kelincahan atlet bulutangkis kelompok umur ganda remaja puteri PB. Djarum pada tes awal 
menunjukkan rentangan nilai tertinggi 14,51 detik dan nilai terendah 12,69 detik dengan rata-rata awal sebesar 13,58, Standar Deviasi (SD) sebesar 0,60 detik, Standar Error Mean (SEMX) sebesar 0,23 detik (lihat tabel 1). hal tersebut dapat terlihat pada distribusi frekuensi dan Grafik batang berikut :

Tabel 2.

Distribusi Frekuensi Pengukuran Tes Awal Court Agility Test

\begin{tabular}{|c|c|c|c|c|}
\hline No. & $\begin{array}{c}\text { Kelas } \\
\text { Interval }\end{array}$ & $\begin{array}{c}\text { Nilai } \\
\text { Teng } \\
\text { ah }\end{array}$ & Fr. A & Fr. R \\
\hline 1 & $\begin{array}{c}12,69- \\
13,13\end{array}$ & 12,91 & 2 & $25 \%$ \\
\hline 2 & $\begin{array}{c}13,14- \\
13,59\end{array}$ & 13,37 & 3 & $37,5 \%$ \\
\hline 3 & $\begin{array}{c}13,60- \\
14,05\end{array}$ & 13,83 & 0 & 0 \\
\hline 4 & $\begin{array}{c}14,06- \\
14,51\end{array}$ & 14,34 & 3 & $37,5 \%$ \\
\hline \multicolumn{3}{|c|}{ Jumlah } & 8 & $100 \%$ \\
\hline
\end{tabular}

Data yang terkumpul di atas menunjukkan bahwa dari 8 sampel yang ada pada tes awal ini, pada kelas interval 12,69 - 13,13 dengan nilai tengah 12,91 terdapat 2 sampel (25\%), pada kelas interval 13,14 - 13,59 dengan nilai tengah 13,37 terdapat 3 sampel $(37,5 \%)$, pada kelas interval 13,60 - 14,05 dengan nilai tengah 13,83 terdapat 0 sampel $(0 \%)$, pada kelas interval 14,06 - 14,51 dengan nilai tengah 14,34 terdapat 3 sampel (37,5\%).

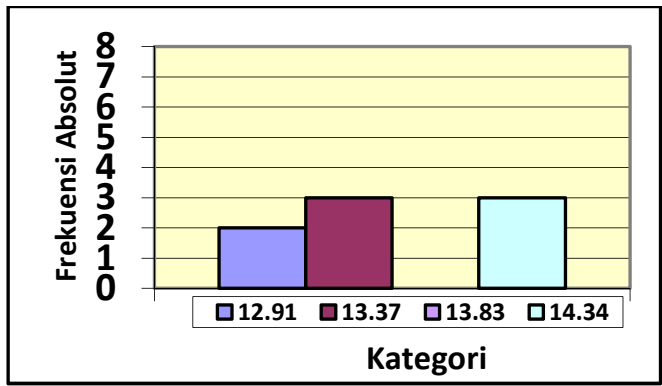

Gambar 19 : Grafik Batang Hasil Tes Awal Court Agility Test b. Tes Akhir

Data yang terkumpul mengenai pengaruh latihan SAQ (Speed, Agility, Quickness) terhadap peningkatan kelincahan atlet bulutangkis kelompok umur ganda remaja puteri PB. Djarum pada tes akhir menunjukkan rentangan nilai tertinggi 13,22 detik dan nilai terendah 11,55 detik dengan rata-rata akhir sebesar 12,38 Standar Deviasi (SD) sebesar 0,53 detik, Standar Error Mean (SEMY) sebesar 0,20 detik (lihat tabel 1). hal tersebut dapat terlihat pada distribusi frekuensi dan grafik batang berikut :

Tabel 3.

Distribusi Frekuensi Pengukuran Tes Akhir Court Agility Test

\begin{tabular}{|c|c|c|c|c|}
\hline No. & $\begin{array}{l}\text { Kelas } \\
\text { Interval }\end{array}$ & $\begin{array}{c}\text { Nilai } \\
\text { Tengah }\end{array}$ & $\begin{array}{r}\text { Fr. } \\
\text {. }\end{array}$ & Fr. $\mathrm{R}$ \\
\hline 1 & $\begin{array}{c}11,55- \\
11,96\end{array}$ & 11,76 & 2 & $25 \%$ \\
\hline 2 & $\begin{array}{c}11,97- \\
12,38\end{array}$ & 12,18 & 1 & $12,5 \%$ \\
\hline 3 & $\begin{array}{c}12,39- \\
12,80\end{array}$ & 12,60 & 4 & $50 \%$ \\
\hline 4 & $\begin{array}{c}12,81- \\
13,22\end{array}$ & 13,02 & 1 & $12,5 \%$ \\
\hline \multicolumn{3}{|c|}{ Jumlah } & 8 & $100 \%$ \\
\hline
\end{tabular}

Data yang terkumpul di atas menunjukkan bahwa dari 8 sampel yang ada pada tes awal ini, pada kelas interval 11,55 - 11,96 dengan nilai tengah 11,76 terdapat 2 sampel (25\%), pada kelas interval 11,97 - 12,38 dengan nilai tengah 12,18 terdapat 1 sampel (12,5\%), pada kelas interval 12,39 - 12,80 dengan nilai tengah 12,60 terdapat 4 sampel (50\%), pada kelas interval 12,81 - 13,22 dengan nilai tengah 13,02 terdapat 1 sampel $(12,5 \%)$. 


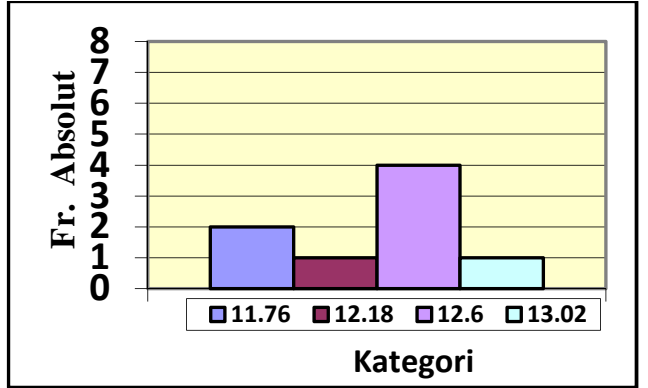

Gambar 20 : Grafik Batang Hasil Tes Akhir Court Agility Test

\section{PEMBAHASAN HASIL PENELITIAN}

Berdasarkan hasil perhitungan statistik untuk hasil data pengukuran Court Agility Test pada kelompok ganda remaja puteri PB. Djarum, yang mana didapat nilai $t$-hitung $=5,71$ lebih besar dari nilai t-tabel $=2,81$ terlihat selisih yang terlampau cukup jauh sehingga menunjukkan bahwa hipotesis alternatif diterima yaitu latihan $S A Q$ berpengaruh terhadap peningkatan kelincahan.

Berdasarkan tabel distribusi frekuensi antara tes akhir dengan tes awal terdapat peningkatan pada kelas ke 3 yang semula tidak ada sampel sama sekali pada tes awalnya namun pada tes akhir mampu meningkat hingga menjadi 4 sampel (50\%). Serta bila dilihat secara rinci, tiap-tiap sampel mengalami peningkatan catatan waktu yang cukup signifikan pada tes akhirnya mengingat peningkatan waktu 0,1 detik saja dalam unsur kecepatan sudah sangat bagus.

Dengan demikian dapat disimpulkan bahwa latihan SAQ (Speed, Agility, Quickness) berpengaruh signifikan terhadap peningkatan kelincahan atlet bulutangkis kelompok umur ganda remaja puteri PB. Djarum.

Oleh karena itu untuk penelitian yang akan datang disarankan agar bisa meminimalisasi kekurangan dan keterbatasan yang sudah diuraikan diatas. Supaya dapat menghasilkan hasil penelitian serta informasi yang jauh lebih akurat dan bermanfaat.

\section{KESIMPULAN}

Berdasarkan masalah yang dikemukakan serta di dukung deskripsi teoritis dan kerangka berpikir serta analisis data, maka hasil tersebut dapat disimpulkan bahwa latihan SAQ (Speed, Agility, Quickness) berpengaruh signifikan terhadap peningkatan kelincahan atlet bulutangkis kelompok umur ganda remaja puteri PB. Djarum.

\section{SARAN}

Hasil penelitian ini, peneliti ingin menyampaikan saran-saran sebagai berikut

1. Kepada peneliti selanjutnya diharapkan dapat melakukan penelitian dengan membuat pengembangan latihan $S A Q$ (Speed, Agility, Quickness) yang lebih bervariasi dan sample lebih besar.

2. Bagi para atlet disarankan saat melakukan latihan dengan materi $S A Q$ (Speed, Agility, Quickness) agar serius dalam berlatih karena latihan ini sangat penting dalam meningkatkan kemampuan bermain bulutangkis.

3. Bagi para mahasiswa maupun alumnus yang telah melatih di berbagai klub bulutangkis, agar terus membuat kreativitas baru, melakukan inovasiinovasi dalam membuat program latihan serta menerapkan ilmu atau pengalaman yang telah didapat selama menuntut ilmu di perkuliahan.

4. Bagi para pelatih PB. Djarum hendaknya memilih calon-calon atlet yang berbakat dengan mempertimbangkan kemampuan kelincahan yang baik. 


\section{DAFTAR PUSTAKA}

Aksan, Hermawan. Mahir Bermain Bulutangkis. Bandung: Nuansa Cendekia. 2012

Alhusin, Syahri. Gemar Bermain Bulutangkis. Surakarta: CV SetiAji. 2007

Ambarukmi, Dwi Hatmisari Dkk. Pelatihan Pelatih Fisik Level 1. Jakarta: Kemenpora. 2007

Bompa, Tudor O. Theory And Methodology Of Training. Dubuque Lowa: Kendall/Hunt Publishing Company. 1994

Brown, Lee E dan Vance A Ferrigno. Training For Speed Agility and Quickness. Usa: Human Kinetics. 2005

Grice, Tony. Petunjuk Praktis Untuk Pemula Dan Lanjut. Jakarta: PT Raja Grafindo Persada. 2007

Hadisasmita, M Yusuf dan Aip Syarifudin. Ilmu Kepelatihan Dasar. Jakarta: Direktorat Jenderal Pendidikan Tinggi. 1996

Lubis, Johansyah. Panduan Praktis Penyusunan Program Latihan. Jakarta: Rajawali Pers. 2013

Mansur dkk. Pelatihan Pelatih Fisik Level 2. Jakarta:ASDEP Pengembangan Tenaga Dan Pembina Keolahragaan. 2009

Massimo, Lucchesi. Attacking Soccer A Tactical Analysis. Pughtown Road Spring City: Reedswain Pubhlising. 2003

Muluk, Dangsina dan Sukadiyanto. Pengantar Teori dan Metodologi Melatih Fisik. Bandung: CV Lubuk Agung. 2011

Noor, Juliansyah. Metodologi Penelitian. Jakarta: Kencana. 2011

Poole, James. Belajar Bulutangkis. Bandung: Pionir Jaya. 2008
Sajoto, M. Peningkatan dan Pembinaan Kekuatan Kondisi Fisik Dalam Olahraga. Semarang: Dahara Prize. 1995

Sudjiono, Anas. Pengantar Statistik Pendidikan. Jakarta: PT Raja Grafindo Persada. 2007

Sugiyono. Metode Penelitian Administrasi. Bandung: Alfabeta. 2009

Sunarno, Agung dan R Syaifullah. Metode Penelitian Keolahragaan. Yogyakarta: Yuma Pustaka. 2009

Tohar. Olahraga Pilihan Bulutangkis. Jakarta: Depdikbud. 1992 